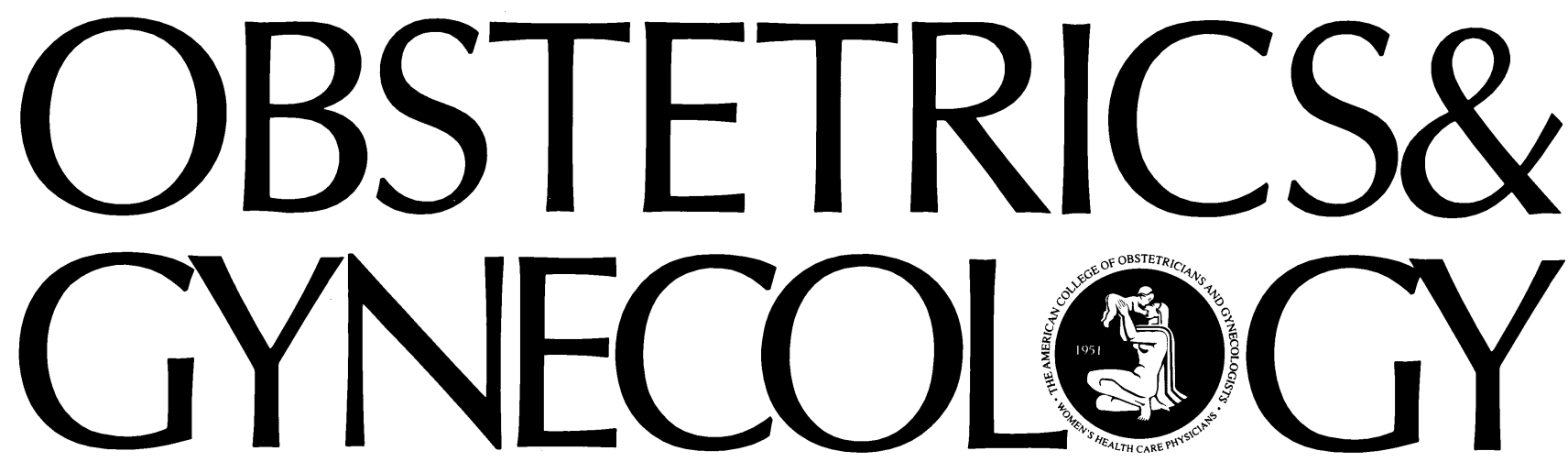

\title{
Continued Follow-up of Pregnancy Outcomes in Diethylstilbestrol-exposed Offspring
}

\author{
RAYMOND H. KAUFMAN, MD, ERVIN ADAM, MD, ELIZABETH E. HATCH, PhD, \\ KENNETH NOLLER, MD, ARTHUR L. HERBST, MD, JULIE R. PALMER, ScD, AND
}

\author{
ROBERT N. HOOVER, MD
}

Objective: To evaluate long-term pregnancy experiences of women exposed to diethylstilbestrol (DES) in utero compared with unexposed women.

Methods: This study was based on diethylstilbestrolexposed daughters, the National Collaborative Diethylstylbistrol Adenosis cohort and the Chicago cohort, and their respective nonexposed comparison groups. Subjects who could be traced were sent a detailed questionnaire in 1994 that contained questions on health history, including information on pregnancies and their outcomes. We reviewed 3373 questionnaires from exposed daughters and 1036 questionnaires from unexposed women.

Results: The response rate was $88 \%$ among exposed and unexposed women. Diethylstilbestrol-exposed women were less likely than unexposed women to have had full-term live

From the Departments of Obstetrics and Gynecology and Epidemiology, Baylor College of Medicine, Houston, Texas; Division of Cancer Epidemiology and National Cancer Institute, Bethesda, Maryland; Department of Obstetrics and Gynecology, University of Massachusetts Medical Center, Worcester, Massachusetts; Department of Obstetrics and Gynecology, University of Chicago, Chicago, Illinois; and Slone Epidemiology Unit, Boston University School of Public Health, Boston, Massachusetts.

This study was supported by contract number N-01CP-50531, Division of Cancer Epidemiology and Genetics/National Cancer Institute, Bethesda, Maryland. births and more likely to have had premature births, spontaneous pregnancy losses, or ectopic pregnancies. Full-term infants were delivered in the first pregnancies of $84.5 \%$ of unexposed women compared with $64.1 \%$ of exposed women identified by record review (relative risk [RR] 0.76, confi-

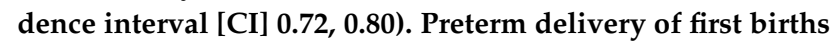
occurred in $4.1 \%$ of unexposed compared with $11.5 \%$ of exposed women, and ectopic pregnancies in $0.77 \%$ of unexposed compared with $4.2 \%$ of exposed women. Spontaneous abortion was reported in $19.2 \%$ of DES-exposed women compared with $10.3 \%$ in control women (RR 2.00, CI 1.54, 2.60). According to complete pregnancy histories (many women had more than one pregnancy), preterm births were more common in DES-exposed women (19.4\% exposed versus $7.5 \%$ unexposed (RR 2.93 CI 2.23, 3.86). Second-trimester spontaneous pregnancy losses were more common in DESexposed women $(6.3 \%$ versus $1.6 \%$; RR 4.25 , CI $2.36,7.66)$. More first-trimester spontaneous abortions occurred in DESexposed women than in controls (RR 1.31, CI 1.13, 1.53), and DES-exposed women had at least one ectopic pregnancy more often than unexposed women (RR 3.84, CI 2.26, 6.54).

Conclusion: Pregnancy outcomes in DES-exposed women were worse than those in unexposed women. (Obstet Gynecol 2000;96:483-9. (C) 2000 by The American College of Obstetricians and Gynecologists.) 
One of the adverse consequences of women's exposure to diethylstilbestrol (DES) in utero has been poor reproductive outcome, ${ }^{1-4}$ and many theories have been put forth in attempts to explain it. Kaufman et $\mathrm{al}^{3}$ found a relationship between structural abnormalities within the uterus and poor pregnancy outcome. Robboy et $\mathrm{al}^{5}$ showed in an athymic mouse model used to grow human embryonic tissues that the inner and outer stromal layers of the uterus did not segregate normally during early phases of pregnancy, which could be a possible cause of uterine and cervical dysfunction. The present study reports the long-term pregnancy experience of women exposed to DES in utero who were observed at several medical centers throughout the United States.

\section{Materials and Methods}

This study is based on two reported cohorts of DESexposed daughters, the National Collaborative Diethylstilbestrol Adenosis cohort ${ }^{6}$ and the Chicago Lying-In Hospital cohort ${ }^{7}$ and their respective nonexposed comparison groups. The former, which provided most of the daughters, was originally assembled during the mid 1970s by review of prenatal records, physician referral, and patient self-referral at four centers, including Houston, Boston, Los Angeles, and Rochester, Minnesota. This population of women was categorized into the following four groups: First, women identified by review of prenatal records in individual physicians' offices or institutions where offspring were born (record review patients). Efforts were made to trace and contact those identified. We invited the DES-exposed daughters to the local clinical center for interview, examination, and enrollment in the long-term program for follow-up. Second, women who presented for examination at the local clinical center with documentation of exposure to DES who were referred by their physicians. Third, documented walk-in patients who came to the project on their own initiative and presented evidence of DES exposure. Fourth, a comparison group of women documented not to have had prenatal exposure to DES, randomly selected on the basis of review of prenatal records and hospital delivery information. These women were selected at the same time as the first group and by the same process, using the same medical record sources. They were matched to women exposed to DES by age (within 6 months) and age of the mother at the index birth (within 5 years). Prenatal records did not mention exposure to any sex hormones (steroidal or nonsteroidal, estrogen, progestens, androgens, or gonadotropins) during the prenatal period. When the study was begun, a sample of 500 unexposed and 500 exposed participants was sufficient to detect, within 5 years and with statistical power of .90 , a fourfold difference between groups in their average annual incidence rates for squamous cervical cancer or severe squamous dysplasia. As the study continued, additional record review women and controls were enrolled. Controls were selected from the same medical records from which DES-exposed record review patients were identified. This was an adequate comparison group at that time (mid 1970s). There are some defects in this control group, such as possible selfselection bias as to who entered the study and who did not. In 1990 it was impossible to collect a comparable group of unexposed women.

Controls were sought only for the record review group of exposed women. An additional source of controls was their sisters, and they comprised $9 \%$ of the comparison group. Eight-hundred twenty-six National Collaborative Diethylstilbestrol Adenosis controls agreed to participate. Women were observed annually with clinical examinations and health questionnaires through 1980. Since then, they have completed periodic health questionnaires only. Women in the National Collaborative Diethylstilbestrol Adenosis study have now been followed up for 15 to 20 years since their enrollment in the program. The known starting date of DES exposure was available in $70 \%$ of women, and $70 \%$ of those were first exposed to DES in the first trimester of pregnancy. The mean duration of DES exposure in the National Collaborative Diethylstilbestrol Adenosis study was 123 days. The doses given to that cohort were difficult to estimate because of incomplete data in the charts, but ranged from a median dose of approximately $1.5-4.5 \mathrm{~g}$.

The Chicago cohort consisted of women from 6-20 weeks' gestation who were enrolled in a clinical trial at the University of Chicago in the early 1950s that examined effects of DES on pregnancy outcome. ${ }^{7}$ Women in the trial were alternately assigned to receive DES or placebo; 840 took graduated amounts of DES according to Smith et $\mathrm{al}^{8}$ and 806 took identical placebo tablets according to the same schedule. Two-hundred thirtythree treated women and 210 unexposed controls agreed to participate in the current study. The Chicago cohort was exposed to high doses of DES, with a median dose of approximately $12 \mathrm{~g}$, whereas the National Collaborative Diethylstilbestrol Adenosis cohort was exposed to more variable doses often based on individual preferences by their physicians. ${ }^{6}$

Detailed information on procedures used in the current study was reported by Hatch et al. ${ }^{9}$ Members of both cohorts were sent detailed questionnaires in 1994 containing questions on health history, pregnancies, and pregnancy outcomes. Subjects who did not receive questionnaires could not be traced or had been unwill- 
Table 1. Study Cohorts by Enrollment Category and Center

\begin{tabular}{|c|c|c|c|c|c|c|c|c|c|c|c|c|c|c|c|c|c|}
\hline \multirow[b]{2}{*}{ Cohort } & \multicolumn{3}{|c|}{ Chicago } & \multicolumn{3}{|c|}{ Boston } & \multicolumn{3}{|c|}{ Mayo Clinic } & \multicolumn{3}{|c|}{ California } & \multicolumn{3}{|c|}{ Baylor } & \multicolumn{2}{|c|}{ Total } \\
\hline & $n$ & $\%$ Row & $\% \mathrm{Col}$ & $n$ & $\%$ Row & $\% \mathrm{Col}$ & $n$ & $\%$ Row & $\% \mathrm{Col}$ & $n$ & $\%$ Row & $\% \mathrm{Col}$ & $n$ & $\%$ Row & $\% \mathrm{Col}$ & $n$ & $\% \mathrm{Col}$ \\
\hline $\begin{array}{l}\text { Record } \\
\text { review }\end{array}$ & 233 & 13.8 & 52.6 & 297 & 17.6 & 23.9 & 498 & 29.6 & 64.3 & 427 & 25.4 & 43.8 & 228 & 13.5 & 23.4 & 1683 & 38.2 \\
\hline $\begin{array}{l}\text { Physician } \\
\text { referral }\end{array}$ & & & & 289 & 27.9 & 23.3 & 66 & 6.4 & 8.5 & 209 & 20.2 & 21.4 & 472 & 45.6 & 48.4 & 1036 & 23.5 \\
\hline Walk-ins & & & & 335 & 51.2 & 27.0 & 24 & 3.7 & 3.1 & 167 & 25.5 & 17.1 & 128 & 19.6 & 13.1 & 654 & 14.8 \\
\hline $\begin{array}{c}\text { Unexposed } \\
\text { controls }\end{array}$ & 210 & 20.3 & 47.4 & 321 & 31.0 & 25.8 & 186 & 18.0 & 24.0 & 172 & 16.6 & 17.6 & 147 & 14.2 & 15.1 & 1036 & 23.5 \\
\hline All & 443 & & & 1242 & & & 774 & & & 975 & & & 975 & & & 4409 & \\
\hline
\end{tabular}

ing to participate in previous follow-up studies. If subjects did not respond after two mailings, a trained interviewer called them. Among those mailed questionnaires in 1994, the response rate was 88\% among exposed and unexposed (two thirds of the questionnaires were returned by mail and one third were telephone interviews). We reviewed a total of 3373 questionnaires from exposed and 1036 from unexposed women (Table 1).

The numbers of pregnancies and pregnancy outcomes were based on patient histories. Women were asked whether they had ever been pregnant and about the number of live births and other outcomes. We asked a detailed question about the outcome of their first pregnancy and their age when it occurred. We also asked about all pregnancy outcomes, including preterm births, first-trimester spontaneous abortions, secondtrimester pregnancy losses, induced abortions, ectopic pregnancies, and stillbirths or neonatal deaths. Specific questions asked about first-trimester pregnancy loss or miscarriage (up to 14th week of pregnancy), secondtrimester pregnancy loss or miscarriage (14th-27th week of pregnancy), and third-trimester pregnancy loss (stillbirths; 28 weeks or later). Preterm birth was defined as birth before 37 weeks of completed gestation, and neonatal death was defined as infant's death in the first month of life.

We compared outcomes of first pregnancies and adverse outcomes reported in all pregnancies among DES-exposed women and controls. Findings were similar between the National Collaborative Diethylstilbestrol Adenosis record review and unexposed groups and the Chicago study treated and control groups (specific data not presented), so both cohorts were grouped for data analysis. Findings also were similar among physician-referred and self-referred exposed groups in the National Collaborative Diethylstilbestrol Adenosis study, so those groups also were combined for major analyses. The proportion of women with selected pregnancy outcomes in their first pregnancies or in any pregnancies was computed for each group (record review, referred or walk-in, and unexposed). Chisquare tests were used to determine statistically significant differences in proportions between exposed and unexposed women, and analysis of variance was used to test for significant differences in means for continuous variables, ${ }^{10}$ using the Epi 6 program (Centers for Disease Control and Prevention, Atlanta, GA). To adjust for potential confounding variables, we computed relative risks (RR) and 95\% confidence limits for individual pregnancy outcomes, comparing exposed with unexposed women and adjusting for cohort and age. A Bernoulli multiplicative model, in which the logarithm of the conditional probability of the event is a linear combination of predictor variables, was assumed for each event conditioned on covariate values. ${ }^{11,12}$ The log likelihood was calculated and standard constrained maximum likelihood methods were applied to estimate coefficients and their standard errors (SE).

\section{Results}

One thousand four hundred fifty DES-exposed women were identified through record review of prenatal records and 233 women were part of the Chicago DES treatment group, for a total of 1683 exposed women, referred to as record review patients. One thousand thirty-six women were referred to National Collaborative Diethylstilbestrol Adenosis centers from practicing physicians and 654 entered as walk-ins (self-referrals). We also reviewed records of 1036 unexposed controls (826 from the National Collaborative Diethylstilbestrol Adenosis group and 210 from the Chicago study).

Demographic data of participants are presented in Table 2. Age at menarche, age at first intercourse, marital status, and race were similar between groups. The mean age at first pregnancy in the record review patients was similar to that of controls (25.1; standard deviation [SD] 5.2 years versus 25.0 SD 5.3 years). However, there was significant difference in mean age 
Table 2. Demographic Data

\begin{tabular}{|c|c|c|c|c|}
\hline & Unexposed & Record review & $\begin{array}{c}\text { Physician and } \\
\text { self-referral }\end{array}$ & $P$ \\
\hline Age at menarche (y) & $12.82 \pm 1.46$ & $12.80 \pm 1.79$ & $12.77 \pm 1.47$ & NS \\
\hline Age at first intercourse (y) & $19.04 \pm 3.11$ & $19.14 \pm 2.93$ & $19.17 \pm 3.09$ & NS \\
\hline Age at first pregnancy (y) & $25.01 \pm 5.29$ & $25.13 \pm 5.20$ & $26.27 \pm 5.01$ & $.001^{* \dagger}$ \\
\hline Age started smoking (y) & $17.78 \pm 3.88$ & $18.42 \pm 3.98$ & $18.15 \pm 3.83$ & $.005^{\ddagger}$ \\
\hline Duration of smoking (y) & $13.58 \pm 8.57$ & $13.77 \pm 8.62$ & $12.07 \pm 7.99$ & $\begin{array}{l}.002^{*} \\
.01^{\dagger}\end{array}$ \\
\hline Smokers over 6 months' duration (\%) & 43.13 & 41.29 & 38.04 & $\begin{array}{l}.001^{*} \\
.01^{\dagger}\end{array}$ \\
\hline Age in 1994 (y) & $42.78 \pm 3.99$ & $42.33 \pm 4.67$ & $40.26 \pm 4.17$ & NS \\
\hline \multicolumn{5}{|l|}{ Race (\%) } \\
\hline White & 97.7 & 97.8 & 98.2 & NS \\
\hline Other & 2.3 & 2.2 & 1.8 & \\
\hline \multicolumn{5}{|l|}{ Marital status (\%) } \\
\hline Married & 72.4 & 72.5 & 74.1 & NS \\
\hline Single & 13.1 & 13.2 & 12.8 & \\
\hline Divorced or widowed & 14.5 & 14.3 & 13.1 & \\
\hline
\end{tabular}

NS = not significant.

* Physician/self-referral versus unexposed. NS = not significant.

† Physician/self-referral versus record review.

¥ Unexposed versus record review.

Data are given as mean \pm standard deviation or $\%$.

at first pregnancy between record review patients and the combined physician referral and walk-in patients $(25.1 \pm 8.2$ years versus $26.3 \pm 5.0$ years, $P<.001)$. There also was a significant difference in the mean age at first pregnancy between controls and the combined physician referral and walk-in patients $(25.0 \pm 5.3$ years versus $26.3 \pm 5.0$ years, $P<.01$ ).

Histories of smoking for 6 months or longer were reported more often in nonexposed than all DESexposed groups. Nonexposed women also began smoking at a statistically significantly earlier mean age than record review women $(17.8 \pm 3.9$ years versus $18.4 \pm$ 4.0 years, $P<.001$ ).

All three groups of DES-exposed women reported more frequent unsuccessful pregnancy attempts for 12 or more months compared with unexposed women (unexposed 19.4\%; record review 31.8\%; physician referrals 39.8\%; walk-ins 37.2\%) $(P<.001)$. Eight hundred thirty-eight $(80.9 \%)$ unexposed women had at least one pregnancy, compared with 1269 (75.4\%) DES-exposed women selected by record review; 776 (73.9\%) exposed women referred by physicians, and $474(72.5 \%)$ walkins. After adjusting for respondents' age and original center, we found that RRs for becoming pregnant at least once, regardless of pregnancy outcome, were also lower among record-review and physician-referred groups than controls (RR 0.93, 95\% CI 0.90, 0.97; RR $0.93,95 \%$ CI $0.88,0.98$, respectively). The findings were not significant when we compared walk-in exposed women with controls (RR 0.92, 95\% CI 0.76, 1.12).

Table 3. Selected Outcomes of First Pregnancies* in Diethylstilbestrol-exposed Compared With Unexposed Daughters ${ }^{\dagger}$

\begin{tabular}{|c|c|c|c|c|c|}
\hline \multirow{3}{*}{$\begin{array}{l}\text { Outcome of first } \\
\text { pregnancy }\end{array}$} & \multirow{3}{*}{$\begin{array}{c}\begin{array}{c}\text { Unexposed } \\
(n=652)\end{array} \\
n(\%)\end{array}$} & \multicolumn{4}{|c|}{ DES exposed $(n=2044)$} \\
\hline & & \multicolumn{2}{|c|}{ Record reviews $(n=1032)$} & \multicolumn{2}{|c|}{ Physician and self-referral $(n=1012)$} \\
\hline & & $n(\%)$ & $\operatorname{RR}(95 \% \mathrm{CI})^{\ddagger}$ & $n(\%)$ & $\operatorname{RR}(95 \% \mathrm{CI})^{\ddagger}$ \\
\hline Full-term live birth & $551(84.5 \%)$ & $662(64.1 \%)$ & $0.76(0.72,0.80)$ & $536(52.9 \%)$ & $0.62(0.58,0.67)$ \\
\hline Preterm birth & $27(4.1 \%)$ & $119(11.5 \%)$ & $3.06(2.03,4.60)$ & $171(16.9 \%)$ & $4.98(3.07,8.08)$ \\
\hline Stillbirth & $2(0.3 \%)$ & $10(0.97 \%)$ & $3.32(0.73,15.1)$ & $14(1.4 \%)$ & $6.32(1.42,28.1)$ \\
\hline Spontaneous abortion & $67(10.3 \%)$ & $198(19.2 \%)$ & $2.00(1.54,2.60)$ & $215(21.3 \%)$ & $1.92(1.43,2.58)$ \\
\hline Ectopic pregnancy & $5(0.77 \%)$ & $43(4.2 \%)$ & $5.34(2.13,13.40)$ & $76(7.5 \%)$ & $9.21(3.73,22.7)$ \\
\hline
\end{tabular}

$\mathrm{DES}=$ diethylstilbestrol; $\mathrm{RR}=$ relative risk; $\mathrm{CI}=$ confidence interval.

* Excludes 638 women who reported an induced abortion in the first pregnancy and 13 women with conflicting pregnancy information.

${ }^{\dagger}$ Adjusted for age and center. Centers where subjects were originally followed up include Baylor College of Medicine, Massachusetts General University of Southern California, and the University of Chicago.

‡ Compared with unexposed. 
Table 4. Selected Pregnancy Outcomes in Any Pregnancy Exposed Versus Unexposed*

\begin{tabular}{|c|c|c|c|c|c|}
\hline \multirow[b]{3}{*}{ Outcome } & \multirow{3}{*}{$\begin{array}{c}\begin{array}{c}\text { Unexposed } \\
(n=838)\end{array} \\
n(\%)\end{array}$} & \multicolumn{4}{|c|}{ DES exposed $(n=2509)$} \\
\hline & & \multicolumn{2}{|c|}{ Record review $(n=1269)$} & \multicolumn{2}{|c|}{ Physician and self-referral $(n=1240)$} \\
\hline & & $n(\%)$ & RR $(95 \%$ CI) & $n(\%)$ & RR (95\% CI) \\
\hline Live birth & $733(87.4 \%)$ & $1076(84.8 \%)$ & $0.95(0.93,0.98)$ & $1000(83.2 \%)$ & $0.96(0.92,1.00)$ \\
\hline Preterm birth ${ }^{\dagger}$ & $59(7.5 \%)$ & $246(19.4 \%)$ & $2.93(2.23,3.86)$ & $281(22.7 \%)$ & $3.72(2.69,5.16)$ \\
\hline $\begin{array}{l}\text { Spontaneous abortion in } \\
\text { first trimester }\end{array}$ & $197(23.5 \%)$ & $375(29.6 \%)$ & $1.31(1.13,1.53)$ & $408(32.4 \%)$ & $1.57(1.32,1.87)$ \\
\hline $\begin{array}{l}\text { Pregnancy loss in } \\
\text { second trimester§ }\end{array}$ & $13(1.6 \%)$ & $80(6.3 \%)$ & $4.25(2.36,7.66)$ & $90(7.1 \%)$ & $5.84(2.88,11.9)$ \\
\hline Ectopic pregnancy & $16(1.9 \%)$ & $90(7.1 \%)$ & $3.84(2.26,6.54)$ & $136(11.4 \%)$ & $5.46(3.11,9.57)$ \\
\hline Induced abortion & $228(27.2 \%)$ & $297(23.4 \%)$ & $0.98(0.84,1.13)$ & $297(20.2 \%)$ & $0.73(0.62,0.86)$ \\
\hline Neonatal death\||II & $3(0.36 \%)$ & $22(1.7 \%)$ & $4.76(1.41,16.1)$ & $21(1.6 \%)$ & $4.51(1.33,15.32)$ \\
\hline
\end{tabular}

$\mathrm{RR}=$ relative risk; $\mathrm{CI}=$ confidence interval.

Record review and physician and self-referral categories are compared with unexposed.

* Adjusted for age of respondent and center. Centers where subjects were originally followed up include Baylor College of Medicine, Massachusetts General Hospital, Mayo Clinic, The University of Southern California, and the University of Chicago.

${ }^{\dagger}$ Defined as more than 3 weeks before the due date.

${ }^{\ddagger}$ Defined as pregnancy loss up to the 14th week of pregnancy.

$\S$ Defined as pregnancy loss from the 15 th to 27 th week of pregnancy.

$\|$ Defined as death of a child in the first month of life.

II Adjusted for age of respondent only because full model did not converge.

Unexposed women were slightly more likely to report induced abortions in their first pregnancies than record-review and physician-referred women, but the rate was similar to that of walk-in patients $(22.2 \%$ unexposed, $18.1 \%$ record review, $15.0 \%$ physician referral, $22.6 \%$ walk-in). The adjusted RRs for induced abortions in first pregnancies were 0.94 (95\% CI 0.84, 1.10), 0.75 (95\% CI 0.61, 0.92), and 0.92 (95\% CI 0.76 , 1.12) in the record review, physician referred, and walk-in groups, respectively, compared with unexposed women. Differences were statistically significant only for the physician-referred patients.

When outcomes of first pregnancies were evaluated, women who had induced abortions were not included because the difference could have skewed results in evaluating frequency of full-term live births in each group. The reasons for induced abortions were not given. Outcomes of first pregnancies, excluding induced abortions, in DES-exposed versus unexposed women are shown in Table 3. Physician-referred or self-referred women are grouped together because data were similar. Overall, DES-exposed women in all groups had poorer outcomes of first pregnancies than unexposed women. Exposed women were less likely to have had full-term live births and were much more likely to have had preterm births, spontaneous abortions, or ectopic pregnancies than unexposed women.

A full-term infant was delivered in the first pregnancy of $84.5 \%$ of unexposed women compared with $64.1 \%$ of the exposed women in the record-review group (RR 0.76, CI 0.72,0.80). Exposed women in the physician-referred/self-referred group were less likely to deliver full-term live infants during their first pregnancies than record-review women $(52.9 \%$ versus $64.1 \%, P<.001)$. Four and one half percent of unexposed women delivered preterm infants (less than 37 completed weeks' gestation) and $0.77 \%$ were diagnosed with ectopic pregnancies. In contrast, in the recordreview DES-exposed cohort, $11.5 \%$ of the women delivered preterm infants (RR 3.06, CI 2.03, 4.60) and 4.2\% were diagnosed with an ectopic pregnancies (RR 5.34, CI 2.13, 13.40). Spontaneous abortions were reported in $19.2 \%$ of the DES-exposed cohort compared with $10.3 \%$ of controls (RR 2.00, CI 1.54, 2.60). Stillbirths occurred more often in DES-exposed women; however, that difference was only statistically significant in the physician-referred/self-referred group $(1.4 \%$ versus $0.3 \%$; $P=.02)$.

Many subjects had more than one pregnancy. Data presented in Table 4 show the frequency with which those women had at least one of the measured pregnancy outcomes and the RR of that outcome. Induced abortions were not excluded because individual women might have had many or no induced abortions, and excluding them might have biased the overall results. Statistically significantly fewer DES-exposed women than controls had at least one or more full-term live births. Among those who did have a live birth, DESexposed women also appeared to have had fewer live births than unexposed women. For example, the recordreview, exposed women were more likely to have had only one birth (RR 1.25, 95\% CI 1.06, 1.49) and slightly 
less likely to have had three or more births (RR 0.85, $95 \%$ CI 0.72, 0.99) compared with unexposed women (data not shown). Similar findings were reported among the physician-referred and walk-in groups. Preterm births were more common in all categories of DES-exposed women compared with unexposed women $(19.4 \%$ in record review [RR 2.93, CI 2.23, 3.86]; and $22.7 \%$ in physician- or self-referred, compared with $7.5 \%$ in the unexposed group [RR 3.72, CI 2.69, 5.16]). Among all DES-exposed women, there was a statistically significantly higher frequency of at least one second-trimester spontaneous pregnancy loss and a significantly greater proportion of first-trimester spontaneous abortions compared with controls. Diethylstilbestrol-exposed women also had ectopic pregnancies (record review $7.1 \%$, physician referred/self-referred $11.4 \%)$ in more of their pregnancies than controls $(1.9 \%)$.

\section{Discussion}

This study, compared with prior reports, is based on the largest number of women with documented in utero exposure to DES to be observed systematically throughout much of their reproductive life span. They are now on average 45 years old, so the present analysis will likely be the last comprehensive study of the reproductive experience of these DES-exposed women. One of the deficiencies of this study was that it was instituted in the mid 1970s. The control or comparison subjects were identified from the same sources as the record review patients, ie, physician and hospital records. We are unable to identify specific reasons why individual women participated or not in the study. The same is true for women in the Chicago cohort, in which study data were collected in the early 1950s. It seems unlikely that the women who originally agreed to participate in the National Collaborative Diethylstilbestrol Adenosis study could have been biased by their prior pregnancy outcomes because almost none of them had conceived before recruitment. No comparison group was obtained for those referred by physicians or came to the clinic on their own. That would require documentation of individuals' nonexposure to DES, which is almost impossible 20 or more years after the fact. We did not control for smoking, race, or chronic hypertension when interpreting our data. Over $95 \%$ of exposed and unexposed women were white. Smoking habits were similar between groups, although nonexposed women were more likely to report smoking; therefore, controlling for it might have had a negative impact on nonexposed women. Chronic hypertension is not associated with DES exposure and was also rare in this group, thus it was not be expected to be an important confounding variable, because a confounder must be strongly associated with both exposure and disease to affect risk estimates.

This review confirmed that pregnancy outcomes for DES-exposed women are significantly worse than those of unexposed women. There is increased frequency of preterm delivery, first-trimester spontaneous abortion, second-trimester pregnancy loss, and ectopic pregnancy. Also, $75.4 \%$ of DES-exposed women became pregnant compared with $81 \%$ of controls. Although the frequency of neonatal death was higher in the DESexposed women than controls, those data were determined to be unreliable.

In first pregnancies, all categories of DES-exposed women had significantly poorer outcomes than controls. Women in the physician-referred or walk-in group had poorer pregnancy outcomes than those of record-review women. Physicians were more likely to refer patients to a DES screening center if they had poor reproductive outcomes or gynecologic abnormalities, which would be true also with women who were self-referred. Therefore, emphasis of our findings should be primarily on record-review patients. Although the physician referred/self-referred group might have been biased, they are included to document differences between those women and record-review women.

One might question the accuracy of data collected many years after an event; however, it appears that recall data on pregnancies is reasonably accurate. Using data from the National Collaborative Diethylstilbestrol Adenosis project, Tilley et $\mathrm{al}^{13}$ compared prenatal records with obstetric histories from women's questionnaires that were completed 10 or more years after the births of their daughters. There was good to excellent agreement in all groups when mothers' recall of personal history (eg, miscarriages and pregnancies) was compared with their medical records ( $\kappa$ related to recall of number of pregnancies of 0.80 ; for recall of miscarriage 0.70 ).

Among DES-exposed women identified by record review, $74.5 \%$ became pregnant $(5.6 \%$ fewer than unexposed controls), and among those women $85 \%$ delivered at least one live full-term infant. Although pregnancy outcomes in DES-exposed women were significantly worse than those of unexposed women, many of the exposed women were able to conceive and deliver a live full-term infant.

Increased frequency of cervical incompetence has been reported in DES-exposed women, ${ }^{14,15}$ and despite difficulty proving its true incidence, this might account for increased frequency of pregnancy loss between weeks 15 and 27 of gestation. Michaels et $\mathrm{al}^{16}$ recommended ultrasound surveillance of the lower uterine 
segment cervix starting at about 14 weeks' gestation to establish early diagnoses of cervical incompetence, and cervical cerclage was done only in women who had that change. Two other reports ${ }^{17,18}$ evaluated the efficacy of prophylactic cerclage placement in women without previous clinical or ultrasound diagnoses of cervical incompetence and with moderate or high risk of preterm delivery. Those authors found that cerclage placement did not prevent preterm delivery and that there were significant risks associated with its use. Like Michaels et al, we have recommended that routine cerclage not be done on all DES-exposed pregnant women because it did not improve pregnancy outcomes. This was verified by Kaufman et $\mathrm{al}^{3}$ in 17 women on whom cervical cerclage was done; they found that on a "routine basis, the same poor pregnancy outcome was observed as in those patients in whom cerclage was not performed."

Even if it is assumed that DES was no longer used in pregnancy after 1971 in the United States (which is not actually the case), there are still many DES-exposed women of reproductive age. Thus, it is important for obstetrician-gynecologists to be aware of the consequences of DES exposure in utero on pregnancy outcome.

\section{References}

1. Barnes AB, Colton T, Gundersen J, Noller KL, Tilley BE, Strama T, et al. Fertility and outcome of pregnancy in women exposed in utero to diethylstilbestrol. N Engl J Med 1980;302:609-13.

2. Herbst AL, Hubby MM, Blough RR, Azizi F. Comparison of pregnancy experience in DES-exposed and DES-unexposed daughters. J Reprod Med 1980;24:62-9.

3. Kaufman RH, Noller K, Adam E, Irwin J, Gray M, Jeffries JA, et al. Upper genital tract abnormalities and pregnancy outcome in diethylstilbestrol exposed progeny. Am J Obstet Gynecol 1984;148: 973-84.

4. Levine RU, Berkowitz KM. Conservative management in pregnancy outcome in diethylstilbestrol-exposed women with and without gross genital tract abnormalities. Am J Obstet Gynecol 1993;169:1125-9.

5. Robboy SJ, Toguchi O, Cunha GR. Normal development of the human female reproductive tract and alterations resulting from experimental exposure to diethylstilbestrol. Hum Pathol 1982;13: 190-8.

6. LaBarthe D, Adam E, Noller KL, O'Brien PC, Robboy S, Tilley BC, et al. Design and preliminary observation of the National Cooperative Diethylstilbestrol Adenosis (DESAD) project. Obstet Gynecol 1978;51:453-8.

7. Dieckman WJ, Davis ME, Ryukiewiez LM, Pottinger RE. Does the administration of diethylstilbestrol during pregnancy have therapeutic value? Am J Obstet Gynecol 1953;66:1062-82.
8. Smith OW, Smith G, Van S. The influence of diethylstilbestrol on the progress and outcome of pregnancy as based on a comparison of treated with untreated primigravidas. Am J Obstet Gynecol 1949;58:994-1009.

9. Hatch EE, Palmer JR, Titus-Ernstoff L, Noller KL, Kaufman RH, Mittendorf R, et al. Cancer risk in women exposed to diethylstilbestrol in-utero. JAMA 1998;280:630-4.

10. Colton T. Statistics in medicine. Boston: Little Brown and Company, 1974.

11. McCullagh P, Nelder JA. Generalized linear models. London: Chapman and Hall, 1983.

12. Gail M. Adjusting for covariates that have the same distribution in exposed and unexposed cohorts. In: Moolgavkar S, Prentice R, eds. Modern statistical methods in chronic disease epidemiology. New York: John Wiley and Sons, 1986:3-18.

13. Tilley BC, Barnes AB, Bergstralh E, LaBarthe D, Noller KL, Colton $\mathrm{T}$, et al. A comparison of pregnancy history recall and medical records. Am J Epidemiol 1985;121:269-81.

14. Ludmir J, Landon MB, Gabbe SG, Samuels P, Mennuti MT. Management of the diethylstilbestrol-exposed pregnant patient: A prospective study. Am J Obstet Gynecol 1987;157:665-9.

15. Ludmir J, Jackson M, Samuels P. Transvaginal cerclage under ultrasound guidance in cases of severe cervical hypoplasia. Obstet Gynecol 1991;78:1067-72.

16. Michaels WH, Thompson HO, Schreiber FR, Berman JM, Ager J, Olson $\mathrm{K}$, et al. Ultrasound surveillance of the cervix during pregnancy in diethylstilbestrol-exposed offsprings. Obstet Gynecol 1989;73:230-9.

17. Rush RW, Isaacs S, McPherson K, Jones L, Chalmers I, Grant A. A randomized controlled trial of cervical cerclage in women at high risk of spontaneous preterm delivery. Br J Obstet Gynaecol 1984; 91:724-30.

18. Lazar R, Gueguen S, Dreyfus J, Renaud R, Pontonnier G, Papiernik $\mathrm{E}$, et al. Multicentered controlled trial of cervical cerclage in women at moderate risk of preterm delivery. Br J Obstet Gynaecol 1984;91:731-5.

Address reprint requests to:

Raymond H. Kaufman, MD

Baylor College of Medicine

Department of Obstetrics and Gynecology

One Baylor Plaza

Houston, TX 77030

E-mail: rkaufman@bcm.tmc.edu

Received January 7, 2000.

Received in revised form April 4, 2000.

Accepted April 27, 2000.

Copyright (C) 2000 by The American College of Obstetricians and Gynecologists. Published by Elsevier Science Inc. 